\title{
Development of a method for assessing the immunological reactivity of the animal body to prevent the development of pathology in the early stages of postnatal development
}

\author{
Alexander Agarkov ${ }^{1, *}$, Edward Gorchakov ${ }^{1}$, Nikolay Agarkov ${ }^{1}$, Natalia Fedota ${ }^{1}$, and \\ Roman Tsygansky ${ }^{1}$
}

${ }^{1}$ Stavropol State Agrarian University, 355019 Serov st., 523, Stavropol, Russia

\begin{abstract}
The study of immunological relationships in the functional system "mother-placenta-offspring" can make a significant contribution to the solution of the issue of improving the safety of the population of newborn animals and poultry. The pathology of the antenatal development of animals has not been sufficiently studied. Antenatal pathology of animals is more often manifested in the form of congenital malformations (anomalies) of development. Congenital defects are usually called those that occur during intrauterine development. However, congenital malformations are also observed in the period of postnatal development as a consequence of a violation of the further formation of organs in animals. There is a need to develop a method for determining the immunological reactivity of the animal body, which would allow to assess the combined functional state of cell-mediated immunological reactivity of innate and acquired immunity in the functional system "mother-placentaoffspring" and determine the factors that cause immunosuppression. Determination of the immunological reactivity of the animal body includes a blood test by conducting a biological test, which uses the biological activity of red blood cells in the Nitroblue Tetrazolium Test and according to their sorption activity-more than $40 \%$ - animals are classified as individuals with reduced immunological reactivity among similar ones.
\end{abstract}

\section{Introduction}

When studying patent and scientific-technical information, several methods for determining immunological reactivity were identified [2-17].

However, the disadvantage of most methods of assessing the immunological reactivity of the body is their emphasis on the ability to assess the cell-mediated immune response [57], which in a living organism is especially important for immunodeficiency and immunosuppression [3-8]. Immunodeficiency is characterized by a decrease in the ability to elicit an effective immune response. Such an incomplete immune response or its absence may be a consequence of primary or acquired (secondary) immunodeficiency [1-16].

\footnotetext{
${ }^{*}$ Corresponding author: agarkov a.v@mail.ru
} 
Currently, the main problem associated with many markers used to monitor and identify immunodeficiency-related diseases is the lack of cellular immunity.

The aim of the proposed work was to develop a method for determining the immunological reactivity of the animal body, aimed at a more relevant assessment of the cell-mediated immunological reactivity of the functional system "mother-offspring" by the reaction of the NBT test.

Disturbances in the placental conditions of fetal development and intrauterine infection in agricultural animals are quite common and are observed in all infectious diseases that have a genetic form of manifestations. Infection of the fetus with sopro is driven by its death, followed by abortion or swelling of offspring with reduced viability.

The pathology of pregnancy with bacterial, mycotic or viral etiology may be due to insemination with animal contamination with sperm and confirmation of the possibility of transplacental transition to excite brucellosis, tuberculosis, leptospirosis, protozoan and viral diseases. The vertical pathway of transmission of the pathogen is considered as one of the important evolutionary mechanisms, with the parasite and providing it with a long-term existence in the host body, and the timely diagnosis of infection of the body during the neonatal period of development is of great importance in the system of anti-episotic measures.

The body's immune system is an indicator system of ecological disadvantage, it effectively responds to changes in environmental conditions. Impaired functions of the immune system (immunodeficiency) are considered as one of the important mechanisms of any pathological process. The most significant are secondary immunodeficiencies. They are due to the influence on the body of various biotic factors (mycotoxins, microorganisms, pathogens of parasitic diseases). In newborn animals, congenital immunodeficiencies are the result of violations of placental development conditions in the fetal period. The main manifestation of immunodeficiencies is increased susceptibility to infectious diseases and a reduced immune response to immunizations. There may be mixed (associated) immunodeficiencies, i.e., pathological conditions due to several factors of different nature.

The methodological basis for assessing the viability of newborn animals is the following scientific provisions:

1. In a functional system mother-fruit-posterity all processes are closely interconnected, interdependent, multidirectional, are characterized by mutual exclusion and are defined by a complex the genotipicheskikh and paratypical factors.

2. The extreme effects of habitat factors on the fetus and offspring are transformed through the mother, as it is the external environment for the fetus, and there is functional integration of the homologous systems of the mother and the fetus in performing homeostatic functions.

3. During fruiting, the maternal body has the ability to accumulate information about various kinds of environmental agents and transmit it to newborns with the beginning of lactation. Experience of maternal body response to extreme exposures biotic and abiotic environmental factors are transmitted to offspring, however, pathology (structural and functional disorders) in the system of the maternal organism is designed for a homologous system in offspring. The structural footprint in a certain system of the maternal organism is formed not only on extreme environmental factors, but also favorable (optimal) conditions that ensure a high level of metabolic, adaptive and reproductive potential in the mother and naturally in the offspring.

4. There is a real possibility of transmitting the immune state of the mother acquired before conception and/or during fruiting to the fetus and newborn. Natural passive immunity in newborns is formed colostrally (with the first feeding with molosive in many infectious diseases brucellosis, salmonellosis, pasteurellosis, escherichiosis, etc.). 
5. Intrauterine infection of offspring in farm animals is recorded in many infections with a genital form of manifestation.

6. Relationships in the mother-fetus functional system during pregnancy are carried out according to the principle of direct and feedback, and the basis of development is the interaction of opposites. These relationships ensure the normal and harmonious development of the fetus and prevent its rejection as a kind of allograft. The immune system of pregnant individuals is tolerant to fetal antigens due to suppressor factors (chorionic gonadotropin and alfafetoprotein).

As for the fetal immune system, it is functionally not yet perfect, areactive and does not enter into an immune conflict with the maternal body. The immune activity of the fetus is formed and develops gradually, depends on the maternal body, [4, 7]

Guided by these scientific provisions, we assumed that stimulation of immunological reactivity in the mother during pregnancy would influence the formation of the fetal immune system

When using the reproductive potential of infected animals during pregnancy, in case of bactero- and/or virusomy, transplacental infection of the fetus occurs with subsequent reproduction of the causative agent in tissues.

The vertical transmission of infection from the mother to the offspring is an important ecological property of the pathogen with enormous epizootic significance. The species of the parasite, at the same time, is preserved from generation to generation, leading to longterm disadvantage in animal populations. The development of ways to block this transmission pathway, especially in viral infections, is a very urgent task. The main reasons for the long-term disadvantage of infectious diseases in productive animals are:

- exploiting the reproductive potential of infected animals;

prenatal infection of offspring and induction of immunological tolerance;

Congenital immunodeficiencies and lifelong persistence of the pathogen;

- use of offspring of infected individuals for tribal or economic purposes

reproductive potential in the mother and naturally in the offspring.

There is a real possibility of transmitting the immune state of the mother acquired before conception and/or during fruiting to the fetus and newborn. Natural passive immunity in newborns is formed colostrally (with the first feeding with molosive in many infectious diseases brucellosis, salmonellosis, pasteurellosis, escherichiosis, etc.).

Intrauterine infection of offspring in farm animals is recorded in many infections with a genital form of manifestation.

Relationships in the mother-fetus functional system during pregnancy are carried out according to the principle of direct and feedback, and the basis of development is the interaction of opposites. These relationships ensure the normal and harmonious development of the fetus and prevent its rejection as a kind of allograft. The immune system of pregnant individuals is tolerant to fetal antigens due to suppressor factors (chorionic gonadotropin and alfafetoprotein).

As for the fetal immune system, it is functionally not yet perfect, areactive and does not enter into an immune conflict with the maternal body. The immune activity of the fetus is formed and develops gradually, depends on the maternal body [4, 7].

Guided by these scientific provisions, we assumed that stimulation of immunological reactivity in the mother during pregnancy would influence the formation of the fetal immune system

When using the reproductive potential of infected animals during pregnancy, in case of bactero- and/or virusomy, transplacental infection of the fetus occurs with subsequent reproduction of the causative agent in tissues.

The vertical transmission of infection from the mother to the offspring is an important ecological property of the pathogen with enormous epizootic significance. The species of 
the parasite, at the same time, is preserved from generation to generation, leading to longterm disadvantage in animal populations. The development of ways to block this transmission pathway, especially in viral infections, is a very urgent task.

\section{Material and methods}

Erythrocyte cells of 42 pregnant sows (the second half of pregnancy) of 3 groups were used as the object of the study, group 4 served as a control red blood cells of 42 pregnant sows (the second half of pregnancy) of 3 groups were used as the object of the study, group 4 served as a control one.

In animals, $500 \mu \mathrm{l}$ of capillary blood was collected in a test tube containing $45 \mu 1$ of the EDTA. After centrifugation and removal of the supernatant, $1.4 \mathrm{ml}$ of $100 \mu \mathrm{m}$ Nile blue sulphate solution was added to $200 \mu \mathrm{l}$ of red blood cell mass. The sample was centrifuged at 3 thousand $\mathrm{rpm}$ for 10 minutes and the supernatant was removed. To $200 \mu \mathrm{l}$ of erythrocyte mass, $1.4 \mathrm{ml}$ of $100 \mu \mathrm{m}$ Nile blue sulphate solution prepared in saline solution with a pH of 7.4 was added. The mixture was incubated at a temperature of $22{ }^{\circ} \mathrm{C}$ for 20 min, then centrifuged for 5-10 min at 3 thousand rpm and the optical density in the supernatant was measured at $630 \mathrm{~nm}$. To exclude a concentration decrease in the optical density of the dye, the selected sample of the supernatant was diluted 2 times with distilled water and the absorption was measured in a $0.5 \mathrm{~cm}$ thick cuvette.

The test groups were subjected to hyperimmunization (associated vaccines were used) during pregnancy, and the control group of animals remained on a trivial (accepted in the farm) antigenic load. The adsorption capacity was carried out during incubation of washed red blood cells (three times) in Hanks solution. (80\% solution of the mixture). Incubation was performed at intervals of 30 minutes to 3 hours. Indicators of adsorption capacity were determined by the degree of inhibition of the NBT test by competent cells (neutrophils).

The technical result is achieved by evaluating the adsorption capacity of red blood cells during incubation in Hanks solution. (80\% solution of the mixture). Incubation is carried out at intervals of 30 minutes to 3 hours. Indicators of adsorption capacity were determined by the degree of inhibition of the NBT test by competent cells (neutrophils). The most active suppression of immunosuppressive properties was found when the biological activity in the NBT test fell to $40 \%$, which is associated with the limit of the receptor capacity of these cells.

\section{Results}

Table 1 shows the indicators of sorption activity of red blood cells of pregnant sows in the NBT test $t \%$. The results obtained indicate a significant variability depending on the groups of animals used in the study (see table 1).

Table 1. Indicators of sorption activity of red blood cells of pregnant sows

\begin{tabular}{|c|c|c|c|c|}
\hline The parameter under study & $\begin{array}{c}1^{\text {st }} \text { test } \\
\text { group }\end{array}$ & $\begin{array}{c}2^{\mathrm{d}} \text { test } \\
\text { group }\end{array}$ & $\begin{array}{c}3^{\mathrm{d}} \text { test } \\
\text { group }\end{array}$ & $\begin{array}{c}4 \text { - control } \\
\text { group }\end{array}$ \\
\hline Suppression of NBTactivity & $35.6 \pm 0.21^{*}$ & $22.8 \pm 0.02$ & $22.6 \pm 0.06$ & $10.5 \pm 0.11^{*}$ \\
\hline $\begin{array}{c}\text { Sorption activity of red blood } \\
\text { cells in the NBT \% }\end{array}$ & $64.2 \pm 0.15$ & $61.8 \pm 0.01$ & $60.2 \pm 0.02$ & $49.8 \pm 0.23$ \\
\hline Suppression of phagocytosis, \% & $18.3 \pm 0.12$ & $20.9 \pm 0.01$ & $14.2 \pm 0.11 *$ & $10.5 \pm 0.21^{*}$ \\
\hline $\begin{array}{c}\text { Sorption capacity in the } \\
\text { phagocytic test \% }\end{array}$ & $52.7 \pm 0.03$ & $60.7 \pm 0.08$ & $54.5 \pm 0.19^{*}$ & $42.5 \pm 0.18^{*}$ \\
\hline \multicolumn{5}{|c|}{ Note: $* \mathrm{P}<0.05$} \\
\hline
\end{tabular}


The sorption activity of red blood cells in the control group of individuals is characterized by a slight drop in biological activity in the NBT test up to $40 \%$. A more noticeable drop in sorption activity was found in the test groups due to changes in protein content, increased elasticity, decreased strength and immunological activity.

Thus, the most active suppression of the immunosuppressive properties of blood was found at biological activity in the NBT test up to $40 \%$, and the increase is associated with the limit of the receptor capacity of these cells.

Therefore, it is advisable to use autologous sorption activity of red blood cells as immunological diagnostic tests to assess the immunological reactivity of individuals.
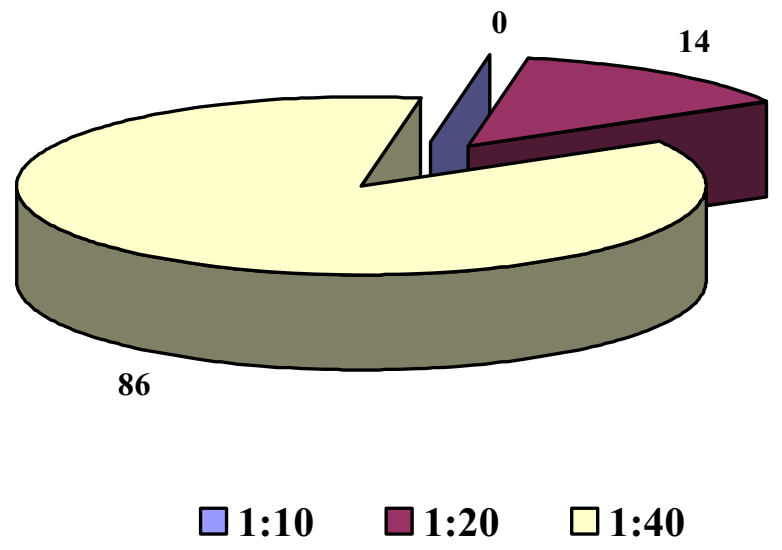

Fig. 1. Distribution of piglets according to degree immunological reactivity of mothers (\%)

Early postnatal losses prevailed in piglets born from sows with 1:40 isoantibody titers, and amounted to $63 \%$. Mortality of piglets whose mothers had lower titers - 1:20 and 1:10, were $30 \%$ and $7 \%$, respectively.

Based on the studies conducted, the relationship between the level of immunological reactivity of mothers and the degree of developmental impairment in newborn piglets was established. It was determined that sows with isoantibody titers 1:40 more often than individuals with lower titers have weak offspring, a high percentage of mortality (in the first group 31.6\%; in the second - 17.3\%).

In order to study the dynamics of progeny development in the postnatal period, further studies were carried out. It is known that in the postnatal period of ontogenesis, physiological mechanisms determine the qualitative and quantitative originality of metabolic functions, gas exchange processes, the constancy of the intracellular medium, which provide maintaining the structural integrity of enzymes, proteins, nucleic acids, and sufficient supply of cells with energy materials.

Therefore, in order to clarify the mechanism for the occurrence of noted developmental disorders in the neonatal and early postnatal periods, particular attention was paid to indicators characterizing the peculiarities of the functioning of cell membranes and biochemical criteria for the level of metabolism in the cell.

The urea hemolysis method was used to assess the permeability level of cell membranes in animal test and control groups (see table 2).

Table 2. Hemolysis method was used to assess the permeability level of cell membranes in animal 


\begin{tabular}{|l|l|l|l|l|}
\hline $\begin{array}{l}\text { Ratio of } \\
\text { isotonic } \\
\text { solution } \\
\text { of sodium } \\
\text { chloride } \\
\text { to urea }\end{array}$ & Group 1 & Group 2 & Group 3 & $\begin{array}{l}\text { Group } \\
\text { control }\end{array}$ \\
\hline $100 / 0$ & $15.2 \pm 0.65^{*}$ & $11.5 \pm 0.27^{*}$ & $6.0 \pm 0.17$ & $6.2 \pm 0.51$ \\
\hline $60 / 40$ & $20.5 \pm 0.76^{*}$ & $16.5 \pm 0.36^{*}$ & $8.3 \pm 0.18$ & $7.7 \pm 0.56$ \\
\hline $50 / 50$ & $61.0 \pm 0.40^{*}$ & $58.3 \pm 0.21^{*}$ & $55.4 \pm 0.17$ & $54.5 \pm 0.37$ \\
\hline $40 / 60$ & $94.6 \pm 0.47^{*}$ & $92.1 \pm 0.21^{*}$ & $88.9 \pm 0.09$ & $91.5 \pm 0.25$ \\
\hline $0 / 100$ & 100 & 100 & 100 & 100 \\
\hline \multicolumn{5}{|c|}{ Note: ${ }^{*} \mathrm{P}<0.05$} \\
\hline
\end{tabular}

The results of the studies showed that in newborn animals with signs of isoimmunization (first group) and non-specific developmental disorders (second group), the percentage of hemolysis is significantly higher than in lambs of the third group and control group, which was indicated by an increase in the permeability of cell membranes in the first and part of the second experimental groups.

Taking into account the features of modern management in the territory of the Stavropol Territory, namely: violation of the ecological system in which all ontogenesis processes take place, error in animal maintenance and feeding technologies, and most importantly ontogenetic development in the conditions of the factor of isoimmunization, we considered it necessary to interpret them as factors that form the stress deadaptation of mothers, and therefore reduce their level of non-specific resistance.

\section{Conclusions}

Based on the study, it can be concluded that the NBT test is practically cost-free: a small amount of blood is needed for the study. In addition, no special equipment is used to perform the analysis. The results of the study can be used in clinical practice to assess the immunological reactivity of the animal body, in particular to the method of assessing immunosuppressive effects in the biological system "mother-offspring" and use the developed immunological diagnostic methods to detect various diseases of the animal body on large and small livestock farms.

\section{References}

1. M. Milovanovic, K. Dietze, V. Milicevic, S. Radojicic, M. Valcic, T. Moritz Hoffmann, BMC Vet Res 15, 56-61 (2017) doi: 10.1186/s12917-019-1831-y

2. A. Brunse, P. Worsoe, S.E. Pors, K. Skovgaard, P.T. Sangild, Shock 51, 337-347. doi: 10.1097/SHK.0000000000001131

3. M. Dennis, J. Eudailey; J. Pollara, A.S. McMillan, K.D. Cronin, P.T. Saha, The urea hemolysis method was used to assess the permeability 93, 64-78 (2013) doi: 10.1128/JVI.01783-18

4. X. Du, S. Chang, W. Guo, S. Zhang, Z.K. Chen, Progress in Liver Transplant Tolerance and Tolerance-Inducing Cellular Therapies, Frontiers in Immunology 11(1326) (2020) doi: 10.3389/fimmu.2020.01326

5. G. Iraola, R. Perez, L. Betancor, A. Marandino, C. Morsella, A. Mendez, BMC Veterinary Research 12, 103-111 (2011) doi: 10.1186/s12917-016-0913-3 
6. M. Seguel, D. Perez-Venegas, J. Gutierrez, Physiological and Biochemical Zoology 92, 326-338 (2014) doi:10.1086/702960

7. D. Karussis, P. Petrou, Immunologic Research 92, 642-648 (2015) doi:10.1007/s12026-018-9032-5

8. J. Dai, X. Yang, Y. Zhu, C. Wang, Cell Therapy Against Cerebral Stroke 50, 37973803 (2017) doi:10.1016/j.transproceed.2018.05.019

9. D. Karussis, P. Petrou, Immunologic Research 7, 368-372 doi:10.1007/s12026-0189032-5

10. A. Rodriguez, M. Atikuzzaman, International Journal of Molecular Sciences 20, 502522 doi:10.3390/ijms20030513

11. V. Battist, L. Maders, M. Bagatini, E. Battisti, Biomedicine \& Pharmacotherapy 67, 203-208 (2013) doi: 10.1016/j.biopha.2012.12.004

12. V. Kim, A. Pham-Huy, E. Grunebaum, Journal of Allergy and Clinical Immunology 143, 403-405 (2019) DOI: 10.1016/j.jaci.2018.04.029

13. B. Overley-Adamson, J. Baez, Feline internal medicine 7, 578-584 (2016) doi:10.1016/B978-0-323-22652-3.00059-1.

14. O. Garden, S. Volk, N. Masson, J. Perry, The Veterinary Journal 240, 6-13 (2018) DOI:10.1016/j.tvj1.2018.08.008

15. A. Matosab, C. Baptistaac, M. Gärtnerad, The Veterinary Journal 193, $24-31$ (2016) doi:10.1016/j.tvj1.2011.12.019

16. H.W. Lee, P. Gangadaran, S. Kalimuthu, B.C. Ahn, Advances in Molecular Imaging Strategies for in Vivo Tracking of Immune Cells, BioMed Research International, 1946585 (2016) doi: 10.1155/2016/1946585

17. J.R. Scalea, Y. Tomita, C.R. Lindholm, W. Burlingham, Transplantation tolerance induction: Cell therapies and their mechanisms, Frontiers in Immunology 7(87) (2016) doi: 10.3389/fimmu.2016.00087 